Research article

Open Access

\title{
Green tea polyphenol epigallocatechin-3-gallate inhibits advanced glycation end product-induced expression of tumor necrosis factor- $\alpha$ and matrix metalloproteinase-13 in human chondrocytes
}

\author{
Zafar Rasheed ${ }^{1}$, Arivarasu N Anbazhagan1, Nahid Akhtar ${ }^{1}$, Sangeetha Ramamurthy ${ }^{1}$, \\ Frank R Voss ${ }^{2}$ and Tariq M Haqqi ${ }^{1}$
}

\begin{abstract}
1Department of Pathology, Microbiology, \& Immunology, School of Medicine, University of South Carolina, 6439 Garners Ferry Rd, Columbia, SC 29209, USA

2Department of Orthopaedics, University of South Carolina, School of Medicine/Palmetto Richland Hospital, Two Medical Park, Columbia, SC 29203, USA
\end{abstract}

Corresponding author: Tariq M Haqqi, Tariq.Haqqi@uscmed.sc.edu

Received: 4 Feb 2009 Revisions requested: 2 Mar 2009 Revisions received: 29 Apr 2009 Accepted: 15 May 2009 Published: 15 May 2009

Arthritis Research \& Therapy 2009, 11:R71 (doi:10.1186/ar2700)

This article is online at: http://arthritis-research.com/content/11/3/R71

(C) 2009 Rasheed et al.; licensee BioMed Central Ltd.

This is an open access article distributed under the terms of the Creative Commons Attribution License (http://creativecommons.org/licenses/by/2.0), which permits unrestricted use, distribution, and reproduction in any medium, provided the original work is properly cited.

\begin{abstract}
Introduction The major risk factor for osteoarthritis $(O A)$ is aging, but the mechanisms underlying this risk are only partly understood. Age-related accumulation of advanced glycation end products (AGEs) can activate chondrocytes and induce the production of proinflammatory cytokines and matrix metalloproteinases (MMPs). In the present study, we examined the effect of epigallocatechin-3-gallate (EGCG) on AGEmodified-BSA (AGE-BSA)-induced activation and production of TNF $\alpha$ and MMP-13 in human OA chondrocytes.

Methods Human chondrocytes were derived from OA cartilage by enzymatic digestion and stimulated with in vitro-generated AGE-BSA. Gene expression of TNF $\alpha$ and MMP-13 was measured by quantitative RT-PCR. TNF $\alpha$ protein in culture medium was determined using cytokine-specific ELISA. Western immunoblotting was used to analyze the MMP-13 production in the culture medium, phosphorylation of mitogenactivated protein kinases (MAPKs), and the activation of NF- $\mathrm{KB}$. DNA binding activity of NF- $\mathrm{B}$ p65 was determined using a highly sensitive and specific ELISA. I $\kappa B$ kinase (IKK) activity was determined using an in vitro kinase activity assay. MMP-13

activity in the culture medium was assayed by gelatin zymography.

Results EGCG significantly decreased AGE-stimulated gene expression and production of TNF $\alpha$ and MMP-13 in human chondrocytes. The inhibitory effect of EGCG on the AGE-BSAinduced expression of TNF $\alpha$ and MMP-13 was mediated at least in part via suppression of p38-MAPK and JNK activation. In addition, EGCG inhibited the phosphorylating activity of IKK $\beta$ kinase in an in vitro activity assay and EGCG inhibited the AGEmediated activation and DNA binding activity of NF- $\kappa B$ by suppressing the degradation of its inhibitory protein $I_{\kappa} B \alpha$ in the cytoplasm.

Conclusions These novel pharmacological actions of EGCG on AGE-BSA-stimulated human OA chondrocytes provide new suggestions that EGCG or EGCG-derived compounds may inhibit cartilage degradation by suppressing AGE-mediated activation and the catabolic response in human chondrocytes.
\end{abstract}

AGE: advanced glycation end product; bp: base pairs; BSA: bovine serum albumin; EGCG: epigallocatechin-3-gallate; ELISA: enzyme-linked immunosorbent assay; FCS: fetal calf serum; H \& E: hematoxylin and eosin; IKK: IкB kinase; IL: interleukin; MAPK: mitogen-activated protein kinase; MMP: matrix metalloproteinase; NF: nuclear factor; OA: osteoarthritis; PBS: phosphate-buffered saline; PCR: polymerase chain reaction; RAGE: receptor for advanced glycation end products; RT: reverse transcriptase; TNF: tumor necrosis factor. 


\section{Introduction}

Osteoarthritis (OA), the most common form of arthritis, is a progressive degenerative joint disease that has a major impact on joint function and the patient's quality of life [1,2]. Many risk factors that contribute to disease onset have been identified, including systemic factors such as genetics, estrogen use, and bone density, and local biomechanical factors such as muscle weakness, obesity, and joint laxity [1]. The most important risk factor for OA besides female sex, obesity, and joint trauma is aging $[1,2]$. How aging contributes to the onset and progression of $\mathrm{OA}$, however, is relatively unknown.

A prominent feature of aging is the modification of proteins by nonenzymatic glycation. Nonenzymatic glycation is a common post-translational modification of proteins caused by reducing sugars. The spontaneous condensation of reducing sugars with free amino groups in lysine or arginine residues on proteins leads to the formation of a reversible Schiff base, which is subsequently stabilized by Amadori rearrangement. The Maillard or browning reaction then converts the initially formed intermediate products into advanced glycation end products (AGEs) [3]. In addition to this classical pathway of AGE formation, it has recently been found that AGE formation can be initiated by metal-catalyzed glucose autooxidation as well as by lipid peroxidation (thereby providing an interesting link between lipid metabolism and the development of $O A$ ).

This diversity in reaction pathways results in a variety of chemical structures of AGEs. Some AGEs are adducts to proteins, while many others present protein-protein crosslinks. Once AGEs are formed, they cannot be removed from the protein; they only leave a tissue when the protein involved is degraded. Articular cartilage collagen has an exceptionally long half-life, and, since the rate of AGE accumulation is largely determined by the rate of protein turnover [4], this low turnover of cartilage constituents results in an abundant accumulation of AGEs in articular cartilage $[5,6]$. The accumulation of AGEs in cartilage leads to inferior mechanical properties $[5,7]$ and to an alteration in cartilage metabolism $[4,8]$. More specifically, cartilage stiffness increases substantially with increasing AGE levels, and matrix synthesis by articular chondrocytes becomes impaired $[5,7,9]$. Accumulation of AGEs, however, is a proposed mechanism for the age-related development of $\mathrm{OA}$ $[3,10]$. Some studies also showed that still-healthy cartilage of patients with a focal degenerative cartilage lesion elsewhere in the joint has higher AGE levels than healthy cartilage from control individuals in which there are no signs of OA [11]. The agerelated accumulation of AGE crosslinks presents a putative molecular mechanism whereby age contributes to the risk of developing OA. The accumulation of AGEs, however, is not only age related. AGE levels tend to be increased in diabetic patients, since the hyperglycemia accelerates AGE formation [12]. The correlation between diabetes mellitus and $O A$ is supported by some older findings showing that radiographic $\mathrm{OA}$ is more common, more severe, and present earlier in patients with diabetes $[13,14]$. In addition, reports from more recent times still show a trend toward correlation of $O A$ with diabetes [15]. OA therefore correlates with both aging and diabetes. In both aging and diabetes, AGE levels are increased. The levels of AGEs might therefore predict susceptibility to OA.

In vivo effects of AGEs on cartilage integrity have been reported in recent studies in beagle dogs and a canine model of $\mathrm{OA}$ induced experimentally by anterior cruciate ligament transection. Animals with elevated AGE levels had more severe OA than did those with normal AGE levels [10]. The mechanism by which AGEs influence cellular function in articular cartilage is poorly understood. The receptor for AGE (RAGE) is expressed in articular chondrocytes and synovial tissue macrophages of individuals with arthritis $[16,17]$. Activation of RAGE by multiple ligands including $\mathrm{S} 100$ protein, high-mobility group box chromosomal protein 1 and AGEs (complex and specific AGEs) in OA chondrocytes and synoviocytes results in increased production of various inflammatory mediators including TNF $\alpha$ and matrix metalloproteinase (MMP)-13 [18-20]. Previous studies have used complexes generated from BSA or a specific AGE, usually pentosidine or N3-carboxymethyllysine, to stimulate OA chondrocytes [2123]. The AGEs used in the current study were produced by reacting endotoxin-free $B S A$ with glycolaldehyde. The resulting AGE-BSA is a complex that includes N3-carboxymethyllysine, pentosidine, and other AGEs [24]. The results of the present study were therefore obtained with a complex of AGEs rather than with a particular AGE. MMPs, a large family of structurally related calcium-dependent and zinc-dependent proteolytic enzymes, are involved in the degradation of many different components of the extracellular matrix $[17,25]$. Both TNF $\alpha$ and MMPs are expressed in a number of different cell types and play a key role in diverse cellular processes, ranging from morphogenesis to tumor invasion to tissue remodeling $[25,26]$. Among the MMPs, MMP-13 (collagenase 3 ) is considered of particular interest due to its ability to digest type-2 collagen.

Green tea (Camellia sinensis), a popular beverage worldwide, has been shown to exert antimutagenic, antiproliferative, and anticarcinogenic effects, as well as anti-inflammatory activity in models of degenerative disorders [27-29]. We have earlier shown that green tea polyphenols inhibit the development of inflammatory arthritis in a mouse model [30] and that epigallocatechin-3-gallate (EGCG), the bioactive constituent of green tea, was nontoxic to human chondrocytes and inhibited the expression of inflammatory mediators in vitro [31-34]. The beneficial effects ascribed to drinking tea are believed to rely on the pharmacological actions of catechins, especially EGCG, and the derivatives of catechin components [35]. The effects of EGCG on AGE-induced damage in arthritis, however, remain to be elucidated. Since high levels of TNF $\alpha$ and MMPs are expressed and produced by AGE-activated human 
OA chondrocytes [18], in the present study we addressed for the first time the question of a possible inhibitory effect of EGCG on AGE-induced expression and production of TNF $\alpha$ and MMP-13 in OA chondrocytes. Our results showed that EGCG suppressed the AGE-induced TNF $\alpha$ and MMP-13 expression and production in $\mathrm{OA}$ chondrocytes, and that these effects were concomitant with inhibited activation of the mitogen-activated protein kinase (MAPK) subgroups p38MAPK and JNK and the activation of the transcription factor $\mathrm{NF}-\mathrm{kB}$. Our results thus identify a unique mechanism of action of a dietary constituent and suggest that use of EGCG or compounds derived from it may have cartilage sparing effect in arthritis.

\section{Materials and methods Specimen selection and articular chondrocyte preparation}

With Institutional Review Board approval, discarded cartilage samples were obtained from the knee joints of 13 OA patients aged 58 to 77 years (mean age, $66 \pm 5.2$ years; 11 female and two male Caucasians) who underwent joint replacement surgery at Palmetto-Richland Hospital, Columbia, SC, USA. The macroscopic cartilage degeneration was determined by staining of femoral head samples with India ink [36], and the cartilage with smooth articular surface (unaffected cartilage) was resected and used to prepare chondrocytes by enzymatic digestion as previously described [31-34,37]. Histological analysis of some of the unaffected cartilage samples was performed on $5-\mu \mathrm{m}$-thick sections stained with $H$ \& $E$ and Safronin O and graded using the Mankin score [38]. Grading of the histology slides (data not shown) revealed that all of the cartilage pieces taken from the unaffected area had a Mankin score $<2$ for structure and a Mankin score of 1 for cellularity. Isolated chondrocytes were plated at a density of $1 \times 10^{6} / \mathrm{ml}$ in $35-\mathrm{mm}$ tissue culture dishes (Corning, NY, USA) in complete Ham's F-12 medium as previously described [31]. In some cases, OA chondrocytes passaged once were used.

\section{Preparation and characterization of AGE-BSA}

AGE-BSA was prepared by reacting BSA (Sigma Chemical Co., St Louis, MO, USA) with glycoaldehyde (Sigma), according to the method described by Valencia and colleagues [21] with slight modifications. Briefly, endotoxin-free BSA (2 mg/ $\mathrm{ml}$ ) was incubated under nonreducing conditions with 70 $\mathrm{mMfresh}$ glycoaldehyde in PBS ( $\mathrm{pH}$ 7.4) without calcium chloride and magnesium chloride for 3 days at $37^{\circ} \mathrm{C}$. The reaction was terminated by removing nonreacted glycoaldehyde by dialyzing extensively against PBS.

Characterization of AGE-BSA was performed as previously described in detail [21-23]. Briefly, the AGE-specific absorbance was read at $340 \mathrm{~nm}$ [21] and AGE-specific fluorescence was detected at excitation/emission wavelengths of $360 / 430$ $\mathrm{nm}$ [22], 330/395 nm, 365/440 nm, 485/530 nm, 280/350 $\mathrm{nm}$ and band widths set at ex40/em40 [23]. All fluorescence data are given normalized to the corresponding control. Absorbance and fluorescence were read using the Synergy HT microplate reader (Biotek Instruction, Winooski, VT, USA). The UV-visible absorption spectra of native BSA and of AGEBSA were recorded on a Shimadzu UV-1800 Spectrophotometer. The electrophoretic migration of native and modified BSA samples was analyzed by reducing SDS-PAGE on $10 \%$ polyacrylamide gel with $4 \%$ stacking gel [39].

\section{Treatment of chondrocytes with AGE-BSA and EGCG}

We first determined whether AGE-BSA and EGCG (purity $\geq$ 95\%, catalogue number E4143; Sigma) affect the viability of OA chondrocytes in vitro. Human OA chondrocytes $\left(1 \times 10^{6} /\right.$ $\mathrm{ml}$ ) were plated in 35-mm culture dishes (Becton-Dickinson, Franklin Lakes, NJ, USA) in complete Ham's F-12 medium and serum-starved for 12 hours/overnight. Chondrocytes were treated with various doses of AGE-BSA (20 to $600 \mu \mathrm{g} / \mathrm{ml}$ ) and EGCG (25 to $200 \mu \mathrm{M}$ ), and after 24 hours the incubation cytotoxicity of AGE-BSA and EGCG was examined using the CytoTox-Glo ${ }^{\text {TM }}$ Cytotoxicity Assay Kit (Promega, Madison, WI, USA). Primary chondrocytes were pretreated with different doses of EGCG for 1 or 2 hours prior to stimulation with AGEBSA. Chondrocytes cultured without AGE-BSA or EGCG served as controls. All experiments were performed within 4 days of the primary culture to avoid dedifferentiation of $O A$ chondrocytes.

\section{Quantitative real-time PCR}

Real-time quantitative PCR was used to quantify the expression of mRNA for TNF $\alpha$ and MMP-13 with expression of GAPDH as endogenous control. Total RNA was separated from OA chondrocytes by the Quick Gene automated system according to the manufacturer's instruction (Quick Gene, Holliston, MA, USA). First-strand cDNA was synthesized using 1 $\mu \mathrm{g}$ total RNA and the SuperScript First Strand cDNA synthesis kit (Invitrogen, Carlsbad, CA, USA). Primers used for PCR assisted amplification were: TNF $\alpha$ (NM_000595: forward, 5'AGG ACG AAC ATC CAA CCT TCC CAA-3'; reverse, 5'-TTT GAG CCA GAA GAG GTT GAG GGT-3'), MMP-13 (NM_002427: forward, 5'-CGC CAG AAG AAT CTG TCT TTA AA-3'; reverse, 5'-CCA AAT TAT GGA GGA GAT GC$3^{\prime}$ ), and GAPDH (NM_002046.3: forward, 5'-TCG ACA GTC AGC CGC ATC TTC TTT-3'; reverse, 5'-ACC AAA TCC GTT GAC TCC GAC CTT-3'). PCR amplification was carried out using the core kit for SYBR Green (Applied Biosystems, Foster City, CA, USA) and the Step One Real Time PCR System (Applied Biosystems). Typical profile times used were an initial step of $95^{\circ} \mathrm{C}$ for 10 minutes, followed by a second step at $95^{\circ} \mathrm{C}$ for 15 seconds and $60^{\circ} \mathrm{C}$ for 60 seconds for 40 cycles with melting curve analysis. The level of target mRNA was normalized to the level of GAPDH and compared with control (untreated sample). Data were analyzed using the $\Delta \Delta C T$ method [40]. 


\section{RT-PCR}

To analyze the transcription of type-2 collagen (COL2A1), type-10 collagen (COL10A1), aggrecan (ACAN), and SRYbox containing gene 9 (SOX-9), total cellular RNA was prepared using a commercially available kit (Qiagen, Valencia, CA, USA). First-strand cDNA was synthesized using $1 \mu \mathrm{g}$ total RNA and the SuperScript First Strand cDNA synthesis kit (Invitrogen). cDNAs of COL2A1, COL10A1, ACAN, and SOX-9 were used as positive controls in the PCR reaction and were generously provided by $\mathrm{Dr}$ Thomas Herring (Department of Orthopaedics, Case Western Reverse University School of Medicine, Cleveland, OH, USA). RT-PCR was carried out utilizing the PTC-100 ${ }^{\mathrm{TM}}$ Peltier Thermal Cycler (MJ Research, Ramsey, MN, USA). Primers used for PCR-assisted amplification were: COL2A1 (NM_001844: forward, 5'-ACG TGA AAG ACT GCC TCA GC-3'; reverse, 5'-TTT CAT CAA ATC CTC CAG CC-3'; expected size of the DNA fragment, 352 bp), COL10A1 (NM_000493: forward, 5'-TGA TCC TGG AGT TGG AGG AC-3'; reverse, 5'-GAG ATC GAT GAT GGC ACT CC-3'; expected size of the DNA fragment, 703 bp); ACAN (NM_013227: forward, 5'-GAC CTG CAA GGA GAC AGA GG-3'; reverse, 5'-CCA CTG GTA GTC CTT GGG CAT-3'; expected size of the DNA fragment, $256 \mathrm{bp})$, and SOX-9 (NM_011448: forward, 5'-GAT TTT TCA CGC AGC CCT AA-3'; reverse, 5'-ATA CAG TCC AGG CAG ACC CA-3'; expected size of the DNA fragment, $637 \mathrm{bp})$. The reaction was cycled according to the following scheme: $40 \mathrm{~min}-$ utes at $72^{\circ} \mathrm{C}$, followed by 40 cycles of 1 minute at $95^{\circ} \mathrm{C}, 1$ minute at $60^{\circ} \mathrm{C}$, and 2 minutes at $72^{\circ} \mathrm{C}$, followed by a final $15-$ minute extension. The amplified products were electrophoresed on $1.2 \%$ agarose gels in TAE buffer and were visualized by ethidium bromide staining.

\section{Cytokine ELISA}

Briefly, OA chondrocytes were stimulated with AGE-BSA $(600 \mu \mathrm{g} / \mathrm{ml})$ for 24 hours with or without pretreatment with EGCG. TNF $\alpha$ present in the culture medium was quantified using the TNF $\alpha$-specific ELISA according to the manufacturer's instructions (R\&D Systems, Minneapolis, MN, USA). Plates were read at $450 \mathrm{~nm}$ using a Synergy HT microplate reader (Biotek Instrument, Winooski, VT, USA).

\section{Western immunoblotting}

Stimulated and control chondrocytes were washed with cold PBS and lysed using the previously described cell lysis buffer (50 mM Tris-HCl, pH 7.4; 150 mM NaCl; 1\% Triton X-100; $0.1 \%$ SDS; $0.5 \%$ sodium deoxycholate; $1 \mathrm{mM}$ EDTA; $1 \mathrm{mM}$ EGTA; Complete ${ }^{\circledR}$ protease and phosphatase inhibitors) [41]. Cytoplasmic and nuclear fractions were prepared as previously described [42]. Total lysate or nuclear/cytoplasmic fraction protein (45 $\mu \mathrm{g} / \mathrm{lane})$ or concentrated cell culture supernatant was resolved by SDS-PAGE (10\% resolving gel with $4 \%$ stacking) and was transferred to nitrocellulose membranes (Bio-Rad, Hercules, CA, USA). Membranes were blocked with blocking buffer containing nonfat dry milk pow- der in Tris-buffered saline and $0.1 \%$ Tween-20. Blots were probed with $1: 200$ to $1: 1,000$ diluted primary antibodies specific for the target protein. Immunoreactive proteins were visualized using 1:1,000 diluted horseradish peroxidase-linked secondary antibodies and enhanced chemiluminescence (GE Healthcare, Milwaukee, WI, USA) [43]. Images were captured using AFP-Imaging System (Minimedical Series, Elms Ford, NY, USA). Anti-MMP-13 antibody (sc-30073) was purchased from Santa Cruz Biotechnology (Santa Cruz, CA, USA), antiNF- $\kappa B$ p65 antibody (IMG-150) was from Imgenex (San Diego, CA, USA), and anti-I $\mathrm{KB} \alpha$ antibody (\#9242), anti-phospho-p38 MAPK antibody (\#9215S), anti-p38 MAPK antibody (\#9212), anti-phospho-SAPK/JNK antibody (\#9251S), antiSAPK/JNK antibody (\#9252), anti-phospho ERK P44/42 MAPK antibody (\#9101S) and anti-ERK P44/42 MAPK antibody (\#9102) were from Cell Signaling Technology (Amherst, Beverly, MA, USA).

\section{Gelatin zymography}

Gelatin zymography was performed essentially as previously described [41]. Briefly, an equal volume of cell culture supernatant was mixed with nonreducing sample buffer (4\% SDS, $0.15 \mathrm{M}$ Tris ( $\mathrm{pH} 6.8$ ), and 20\% (volume/volume) glycerol containing $0.05 \%$ (weight/volume) bromophenol blue) and resolved on a $10 \%$ polyacrylamide gel containing copolymerized $0.2 \%$ gelatin (Bio-Rad). Commercially available MMP-13 (catalogue number PF094; EMD Chemicals, Gibbstown, NJ, USA) was used as a positive control. The product used was supplied as concentrated conditioned medium, and $2.5 \mu \mathrm{l}$ was used. After electrophoresis, gels were washed twice, for 15 minutes each time, with $2.5 \%$ Triton X-100. Digestion was carried out by incubating the gel in the gelatinase buffer $(50 \mathrm{mM}$ Tris- $\mathrm{HCl}\left(\mathrm{pH} \mathrm{7.6)}, 10 \mathrm{mM} \mathrm{CaCl}_{2}, 50 \mathrm{mM} \mathrm{NaCl}\right.$, and $0.05 \%$ Brij-35) at $37^{\circ} \mathrm{C}$ for 16 hours. The gel was stained with $0.1 \%$ Coomassie brilliant blue R350 (GE Healthcare, Piscataway, NJ, USA), and the locations of gelatinolytic activity were revealed as clear bands on a background of uniform light blue staining. Electrophoretic migration of MMP-13 in the supernatant was compared with known molecular weight standards and also with clear bands of MMP-13 activity produced by the positive control. After development, gel images were captured and the clear bands were analyzed using Un-Scan-It software (Silk Scientific Corporation, Orem, UT, USA).

\section{NF- $\kappa B$ DNA binding activity assay}

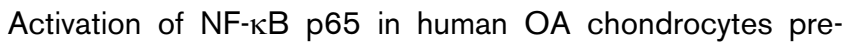
treated with EGCG and then stimulated with AGEs was determined using a highly sensitive and specific Transcription Factor ELISA Kit according to the instructions of the manufacturer (catalogue number EK1121; Panomics, Fremont, CA, USA). The color intensity was read at $450 \mathrm{~nm}$ using the Synergy HT ELISA plate reader (Biotek). 


\section{In vitro IKK $\beta$ kinase assay}

The effect of EGCG on purified I $\mathrm{KB}$ kinase (IKK) activity was determined with a highly sensitive HTScan ${ }^{\circledR}$ IKK $\beta$ Kinase Assay Kit according to the instructions of the manufacturer (catalogue number 7549; Cell Signaling Technology). The kit provides a means of performing kinase activity assays with recombinant human IKK $\beta$ kinase. It includes active IKK $\beta$ kinase (supplied as GST fusion protein), a biotinylated peptide substrate, and a phospho-serine antibody for detection of the phosphorylated form of the substrate peptide. Purified IKK $\beta$ kinase was pretreated with different doses of EGCG (5 to 200 $\mu \mathrm{M}) 5$ minutes prior to the treatment of substrate peptide. The assay was performed on a 96-well high-binding streptavidincoated plate, and the absorbance $(A)$ of each well was read at $450 \mathrm{~nm}$ using the Synergy HT ELISA plate reader (Biotek). Each kinase assay was performed in triplicate. The percentage inhibition of IKK $\beta$ kinase activity was calculated using the formula:

percentage inhibition $=1-\left[\left(A_{\text {inhibited }}-A_{\text {blank }}\right) /\left(A_{\text {uninhibited }}-A_{\text {blank }}\right)\right] \times 100$ Densitometric analysis

Measurements of the scanned bands were performed using Un-Scan-It software. Each band was scanned five times, and the mean band intensity (pixels per band) was obtained. Data were normalized to suitable loading controls and expressed as the mean \pm standard deviation followed by appropriate statistical analysis.

\section{Statistical analysis}

All measurements were performed in duplicate and were repeated at least three times using different age-matched and sex-matched OA samples. All statistical analyses were performed using Origin 6.1 software package (one-paired twotailed $t$ test with one-way analysis of variance and Tukey's post-hoc analysis) and $P<0.05$ was considered significant. Values shown are the mean \pm standard error of the mean unless stated otherwise.

\section{Results}

\section{Characterization of AGE-BSA}

Glycoaldehyde-induced modifications of BSA were studied by UV-visible absorption spectroscopy, gel electrophoresis, and AGE-specific fluorescence. The absorption spectra of AGEBSA (AGEs) revealed a marked UV hyperchromicity $(74.4 \%)$ at $280 \mathrm{~nm}$ (Figure 1a). For further characterization of in vitroproduced AGEs, samples were analyzed by SDS-PAGE under reducing conditions. An accompanying decrease in the electrophoretic mobility and smear towards higher molecular size ranges from 65 to $98 \mathrm{kDa}$ was noted, indicating a higher level of glycoaldehyde-mediated modifications (Figure 1b). AGE-specific absorbance was detected at $340 \mathrm{~nm}$ [21] and was found to be significantly high in glycoaldehyde-treated BSA as compared with native BSA $(P<0.001)$. AGE-specific fluorescence was detected at the excitation/emission wavelengths described elsewhere [22,23] and were found to be
Table 1

Characterization of native BSA and AGE-BSA under identical experimental conditions

\begin{tabular}{lll}
\hline Parameter & AGE-BSA & Native BSA (control) \\
\hline$A_{340}$ & $0.625 \pm 0.13^{\star}$ & $0.228 \pm 0.05$ \\
Fluo [ex 360/em $430 \mathrm{~nm}]$ & $749.4 \pm 19.5^{\star \star}$ & $80.4 \pm 4.8$ \\
Fluo [ex 330/em $395 \mathrm{~nm}]$ & $754.6 \pm 17.2^{\star *}$ & $83.2 \pm 5.7$ \\
Fluo [ex 365/em $440 \mathrm{~nm}]$ & $741.4 \pm 28.1^{\star *}$ & $84.8 \pm 5.2$ \\
Fluo [ex 485/em $530 \mathrm{~nm}]$ & $734.1 \pm 20.4^{\star *}$ & $85.1 \pm 5.3$ \\
Fluo [ex 280/em $350 \mathrm{~nm}]$ & $733.2 \pm 19.1^{\star *}$ & $84.0 \pm 4.4$ \\
\hline
\end{tabular}

Data expressed as the mean \pm standard deviation of 12 independent assays. $A_{340}$, absorbance at $340 \mathrm{~nm}$; AGE, advanced glycation end product; Fluo [ex/em], fluorescence [excitation/emission], Band width was set at $40 / 40$ for fluorescence measurement. ${ }^{\star} P<0.01$ versus control, ${ }^{\star \star} P<0.0001$ versus control.

very high for glycoaldehyde-treated BSA compared with native BSA, signifying the presence of a higher level of modifications. Characterization of AGE-specific modifications on BSA resulting from incubation with glycoaldehyde is summarized in Table 1.

\section{Human chondrocytes in monolayers maintain their chondrogenic phenotype}

We determined whether primary human $O A$ chondrocytes and chondrocytes passaged once used in these studies maintained their phenotype - by analyzing the expression of type-2 collagen, aggrecan, and SOX-9 mRNA, which are considered to be signatures of the chondrogenic phenotype [44]. Our results show that primary or passage-1 human OA chondrocytes in monolayer culture maintained their phenotype, when they were plated $\left(1 \times 10^{6} / \mathrm{ml}\right)$ in $35-\mathrm{mm}$ culture dishes in complete Ham's F-12 medium with 10\% FCS and were allowed to grow at $37^{\circ} \mathrm{C}$ and $5 \% \mathrm{CO}_{2}$ in a tissue culture incubator, as judged by the continued expression of COL2A1 (Figure 2a), aggrecan, and SOX-9 mRNAs, whereas COL10A1 mRNA was not expressed (Figure 2b). Based on these data, OA chondrocytes were used within 72 hours after plating to avoid possible dedifferentiation.

\section{Induction of TNF $\alpha$ and MMP-13 expression by AGE-BSA in human osteoarthritis chondrocytes}

OA chondrocytes were treated with increasing doses of AGEBSA (20 to $600 \mu \mathrm{g} / \mathrm{ml}$ ) and the mRNA expression of TNF $\alpha$ and MMP-13 was determined using a highly sensitive and specific quantitative RT-PCR method. We found AGE-BSA dosedependently induced TNF $\alpha$ and MMP-13 mRNA expressions, and the maximum stimulation of chondrocytes was found to be at $600 \mu \mathrm{g} / \mathrm{ml} \mathrm{AGE-BSA} \mathrm{(data} \mathrm{not} \mathrm{shown).} \mathrm{Based} \mathrm{on} \mathrm{these}$ data, we used a concentration of $600 \mu \mathrm{g} / \mathrm{ml} \mathrm{AGE-BSA} \mathrm{for}$ stimulation of chondrocytes in all of our experiments. 
(a)

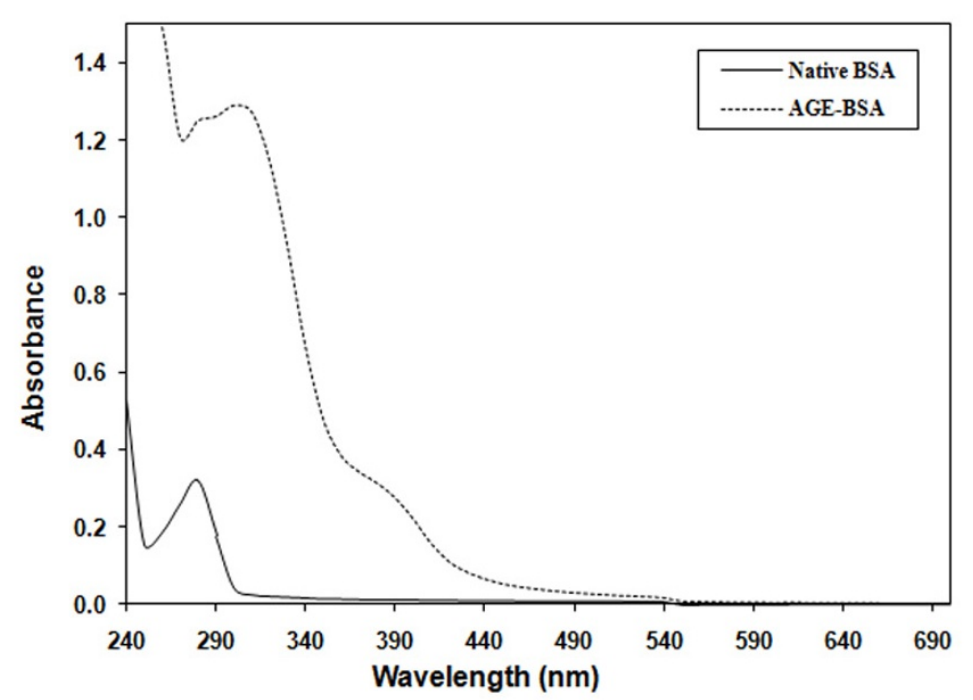

(b)

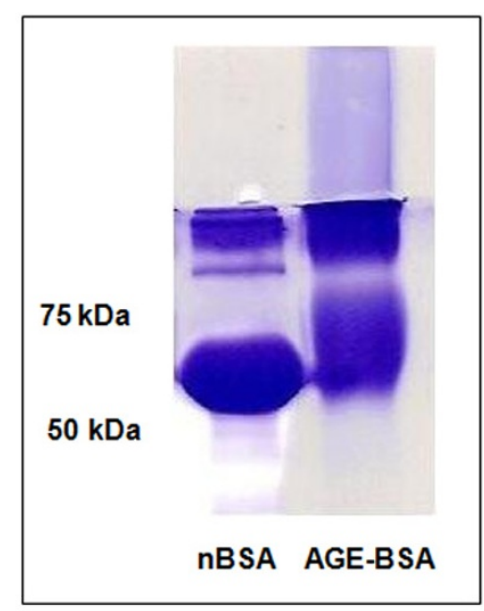

Absorbance spectra and electrophoresis of native BSA and advanced glycation end product-BSA. (a) Absorbance spectra of native BSA and advanced glycation end product (AGE)-BSA. Samples were incubated with or without glycoaldehyde in PBS, pH 7.2, with equal protein concentrations. (b) Electrophoresis of native BSA and AGE-BSA. Samples were electrophoresed using 10\% SDS-PAGE with 4\% stacking gel. The gel was run for 1.5 hours at $125 \mathrm{~V}$. The precision plus protein standard (Bio-Rad) served as the molecular size marker. AGE-BSA was derived from the reaction between endotoxin-free BSA $(2 \mathrm{mg} / \mathrm{ml})$ and glycoaldehyde $(70 \mathrm{mM})$.

\section{Effect of EGCG on AGE-BSA-induced expression and production of TNF $\alpha$ in osteoarthritis chondrocytes}

OA chondrocytes (80\% confluent) were pretreated with EGCG (25 to $150 \mu \mathrm{M})$ for 2 hours, and were then stimulated with in vitro-generated AGE-BSA $(600 \mu \mathrm{g} / \mathrm{ml})$ for 8 hours. No cytotoxic effect of EGCG was noted at the dose used (data not shown). The level of TNF $\alpha$ mRNA was quantified by a highly sensitive and specific quantitative RT-PCR method, and values were compared with control. Our results showed that OA chondrocytes treated with AGE-BSA had a higher level of TNF $\alpha$ mRNA compared with unstimulated OA chondrocytes. TNF $\alpha$ mRNA levels showed a marked decline, however, in the samples pretreated with EGCG and then stimulated with AGE-BSA (Figure 3a). To determine whether inhibition of gene expression also affected the protein level, culture supernatants were assayed for TNF $\alpha$ protein using TNF $\alpha$-specific ELISA. As shown in Figure 3b, pretreatment with 25 to 150 $\mu M$ EGCG significantly decreased the AGE-BSA-induced TNF $\alpha$ production in the culture supernatant of AGE-BSA-stimulated OA chondrocytes. It is also to be noted that maximum suppression was observed in cultures treated with $75 \mu \mathrm{M}$ EGCG, after which no further decline was found (Figure 3b).

\section{EGCG downregulated the expression and production of MMP-13 in AGE-BSA-stimulated osteoarthritis chondrocytes}

Pretreatment of OA chondrocytes with EGCG inhibited AGEBSA-induced gene expression of MMP-13 in a dose-depend- ent manner as determined by quantitative RT-PCR (Figure 4a). Again the maximum inhibitory effect of EGCG was found at 75 $\mu \mathrm{M}$ concentration. We also determined the effect of EGCG on the production of MMP-13 in the culture supernatant by western immunoblotting using anti-MMP-13 antibody (Figure 4b). Analysis of the immunoblot revealed that the levels of MMP-13 were high in the supernatant of chondrocytes treated with AGE-BSA when compared with the levels detected in untreated chondrocytes culture, where MMP-13 was barely detectable. Importantly, the AGE-BSA-stimulated increase in MMP-13 expression was inhibited by EGCG to less than the basal level (Figure 4b). These results were further verified using gelatin zymography (Figure 4c). Zymographic analysis showed that OA chondrocytes stimulated with AGE-BSA had enhanced levels of active MMP-13 compared with the levels detected in control OA chondrocytes. Importantly, chondrocytes pretreated with different doses of EGCG and then stimulated with AGE-BSA showed reduced levels of active MMP13 in the culture supernatant. Taken together these data indicate that the AGE-BSA-induced production of active MMP-13 was inhibited by EGCG in human OA chondrocytes (Figure 4c).

Effect of EGCG on the activation of MAPKs in AGE-BSAstimulated osteoarthritis chondrocytes

Activation of MAPKs is intimately associated with the expression of proinflammatory mediators [26]. To determine whether the inhibition of TNF $\alpha$ and MMP-13 expressions was due to 
Figure 2

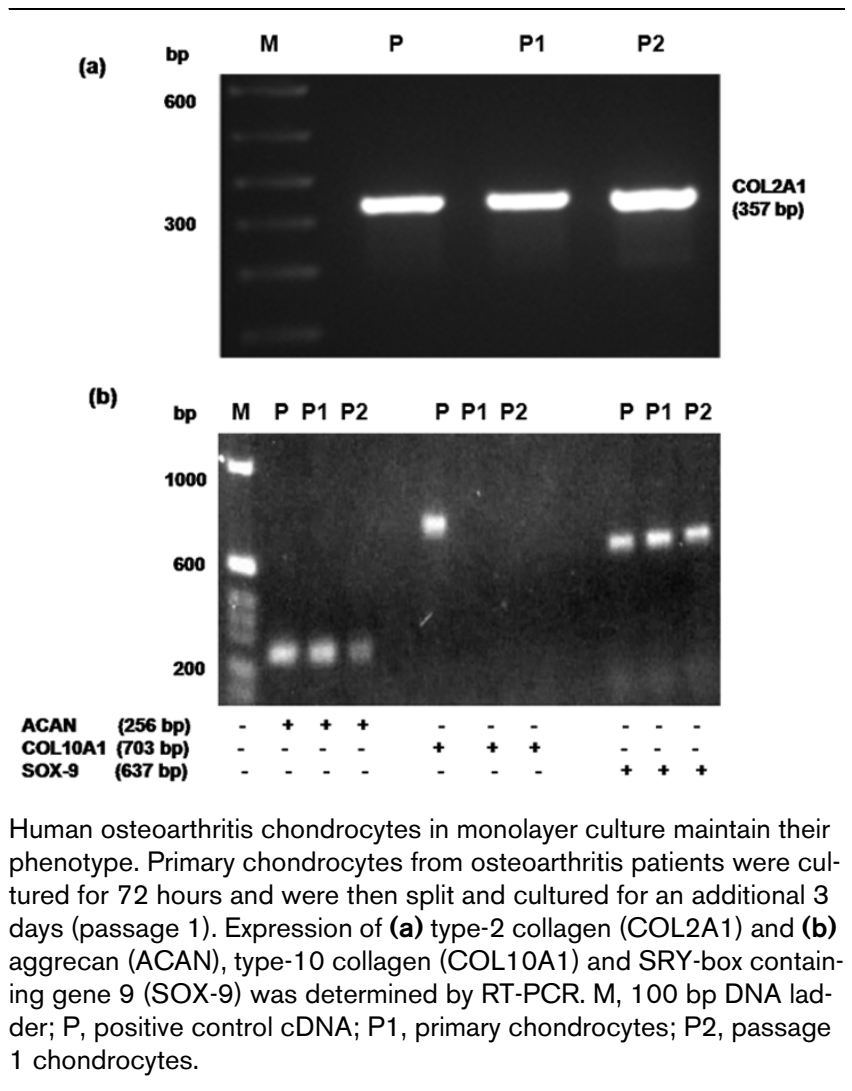

EGCG-mediated inhibition of the MAPK pathway, we examined the effect of EGCG on the activation of MAPKs in AGEBSA-stimulated human $O A$ chondrocytes. OA chondrocytes were pretreated with EGCG (25 to $150 \mu \mathrm{M})$ for 1 hour and then stimulated with AGE-BSA for 45 minutes, and the cell lysate was analyzed by western immunoblotting. Pretreatment of chondrocytes with EGCG attenuated the AGE-BSAinduced phosphorylation of p38-MAPK, JNK-MAPK and to a lesser extent of ERK-MAPK (Figure 5a,b). To further strengthen the relation of p38, JNK and ERK inhibition by EGCG and proinflammatory cytokine TNF $\alpha$ and MMP-13 expressions in AGE-BSA-stimulated human OA chondrocytes, we used pharmacological agents that inhibit p38-, JNKand ERK-MAPKs.

Treatment of OA chondrocytes with the selective p38 inhibitor SB202190 (100 $\mu \mathrm{M})$, the JNK inhibitor SP600125 (10 $\mu \mathrm{M})$, and the ERK inhibitor PD98059 $(50 \mu \mathrm{M})$ blocked the AGEBSA-induced TNF $\alpha$ mRNA expression as determined by quantitative RT-PCR, but the effect was more pronounced in the case of p38-MAPK and JNK (Figure 3a). AGE-BSAinduced MMP-13 mRNA expression was significantly inhibited by SB202190 and SP600125 $(P<0.05)$, but the affect was more pronounced when SB202190 was used. Pretreatment of OA chondrocytes with PD98059 had no effect on MMP-13 mRNA expression in AGE-BSA-stimulated OA chondrocytes
(Figure 4a). These data support the contention that inhibition of AGE-BSA-induced TNF $\alpha$ (Figure $3 \mathrm{a}$ ) and MMP-13 (Figure 4a) expressions by EGCG in OA chondrocytes was mediated, at least in part, by the inhibition of AGE-induced activation of the p38-MAPK and JNK-MAPK pathways.

\section{Effect of EGCG on NF- $\kappa$ B activation in AGE-BSA- stimulated osteoarthritis chondrocytes}

NF- $\kappa \mathrm{B}$ is an important transcriptional regulator of inflammatory cytokine gene expression and plays a crucial role in immune and inflammatory response. After the ubiquitination and phosphorylation of $I_{\kappa} B \alpha$, the inhibitor is degraded and the NF- $\kappa B$ is translocated to the nucleus, where it binds and activates the promoter of target genes. To investigate the mechanism responsible for the inhibitory effect of EGCG on proinflammatory cytokine gene expression, we examined the effect of EGCG on NF- $\kappa B$ activation and translocation to the nucleus using western blotting. Stimulation of $O A$ chondrocytes with AGE-BSA induced the degradation of $l_{\kappa} B \alpha$ and nuclear translocation of NF- $\kappa B$ p 65 (Figure $6 a, b)$. Pretreatment with EGCG (25 and $75 \mu \mathrm{M}$ ) inhibited the AGE-BSA-induced degradation

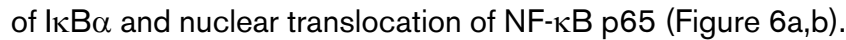
To determine whether EGCG also inhibits AGE-BSA-induced DNA binding activity of NF- $K B$, we used the Transcription Factor ELISA kit. Exposure of OA chondrocytes to AGE-BSA significantly enhanced the DNA binding activity of NF- $\mathrm{B}$ p65 compared with controls $(P<0.0001)$, and increasing doses of EGCG (25 to $75 \mu \mathrm{M})$ significantly reduced the AGE-BSAinduced DNA binding activity of NF- $\kappa B$ p65 $(P<0.05)$ (Figure 6c).

To further strengthen the relation of inhibition of the NF- $\kappa B$ pathway and the expression of TNF $\alpha$ in our studies, we next investigated the effect of a pharmacological agent (MG-132, a known inhibitor of NF- $\mathrm{BB}$ ) on the expression of TNF $\alpha$ and MMP-13. Treatment of chondrocytes with the proteasome inhibitor MG-132 (100 $\mu \mathrm{M})$ significantly blocked the AGEBSA-induced TNF $\alpha$ expression $(P<0.05)$ (Figure 3a), whereas MMP-13 mRNA expression was also inhibited by MG-132 but the inhibition was not statistically significant $(P>$ 0.05) (Figure 4a). Together these results suggest that EGCG exerts its inhibitory effect on TNF $\alpha$ expression in AGE-BSAstimulated $\mathrm{OA}$ chondrocytes via modulation of the activation and DNA binding activity of NF- $\kappa \mathrm{B}$.

\section{Inhibition of IKK $\beta$ kinase activity by EGCG}

The effect of EGCG on the phosphorylating activity of IKK $\beta$ kinase was determined using an HTScan ${ }^{\circledR}$ IKK $\beta$ Kinase Assay Kit (Cell Signaling Technology). Purified IKK $\beta$ kinase was pretreated with different doses of EGCG ( 5 to $200 \mu \mathrm{M}) 5$ minutes prior to incubation with the substrate peptide. Figure $6 \mathrm{~d}$ shows that IKK $\beta$ kinase activity was significantly inhibited by EGCG treatment $(P<0.001)$. A maximum of $85 \%$ inhibition of enzymatic activity was observed with $5 \mu \mathrm{M}$ EGCG, after which no significant inhibition $(P>0.05)$ of enzyme activity was 
(a)

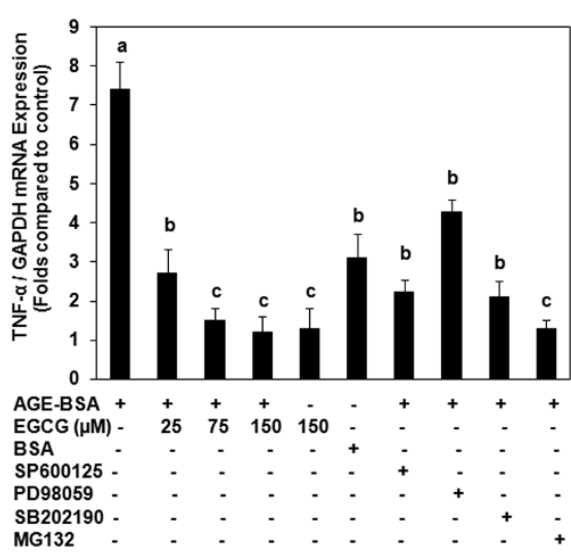

(b)

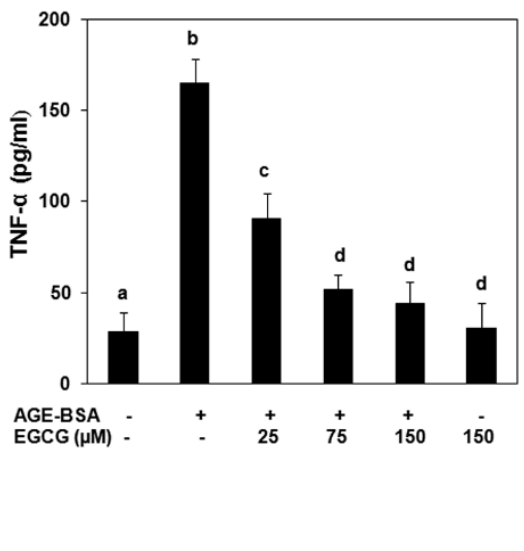

Gene expression and production of TNF $\alpha$ in advanced glycation end product-BSA-stimulated osteoarthritis chondrocytes. (a) Effect of epigallocatechin-3-gallate (EGCG), specific inhibitors for mitogen-activated protein kinases and NF- $\kappa B$ on the gene expression of TNF $\alpha$ in advanced glycation end product (AGE)-BSA-stimulated osteoarthritis (OA) chondrocytes. Primary chondrocytes were pretreated with EGCG (25 to $150 \mu \mathrm{M})$ for 2 hours and were stimulated by AGE-BSA $(600 \mu \mathrm{g} / \mathrm{ml})$ for 8 hours. Folds of TNF $\alpha$ mRNA expression, as compared with control and normalized to GAPDH, were determined by quantitative RT-PCR. Concentrations of specific inhibitors of JNK (SP600125), ERK (PD98059), p38 (SB202190) and NF-KB (MG-132) used in these studies were $10 \mu \mathrm{M}, 50 \mu \mathrm{M}, 100 \mu \mathrm{M}$ and $100 \mu \mathrm{M}$, respectively. Native BSA (600 $\mu \mathrm{g} / \mathrm{ml})$ was used as a negative control. (b) Effect of EGCG on the production of TNF $\alpha$ in AGE-BSA-stimulated OA chondrocytes. Primary chondrocytes were pretreated with EGCG $(25$ to $150 \mu \mathrm{M})$ for 2 hours and were stimulated by AGE-BSA $(600 \mu \mathrm{g} / \mathrm{ml})$ for 24 hours. The production level of TNF $\alpha$ was determined by sandwich ELISA. Results are representative (mean \pm standard error of the mean) of duplicate experiments with OA chondrocytes obtained from five age-matched and sex-matched OA donors; data without a common letter differ, $P<0.05$.

observed (Figure 6d). These data suggest that EGCG suppresses the activation of NF- $\mathrm{BB}$ by inhibiting the enzyme activity of IKK complex.

\section{Discussion}

Chondrocytes are the only cellular components of cartilage. Under normal physiologic conditions, chondrocytes maintain an equilibrium between anabolic and catabolic activities that is necessary for preservation of the structural and functional integrity of the tissue. Chondrocytes express inflammatory mediators such as TNF $\alpha$ and proteolytic enzymes - aggrecanases and MMPs - which under normal conditions, mediate a very low matrix turnover required for cartilage remodeling [45]. However, in pathologic conditions such as OA, however, chondrocyte production of these inflammatory mediators and enzymes increases considerably, resulting in cartilage destruction [46].

Age is by far the most important risk factor for the development of OA [45]. By which mechanism aging is involved in the development of this debilitating disease remains largely unknown. Fatigue failure of the cartilage collagen network due to repetitive loading has long been recognized as one of the mechanisms involved in the development of OA [46]. With increasing age, the strength of the collagen matrix to withstand loading diminishes. Age-related changes in articular cartilage that influence the composition and strength of the cartilage matrix are therefore very probably involved in the development of OA $[47,48]$. One such change, the age-related accumulation of AGEs, has previously been shown to increase tissue stiffness, to decrease extracellular matrix turnover (synthesis and degradation), and to affect many cellular processes [17]. It is well documented that human chondrocytes are highly responsive to AGEs [18-20], and the most striking effect of AGEs or AGE-BSA on chondrocytes is to induce the production of TNF $\alpha$ [18] and MMP-13 [18,19], which are important sources of inflammation and cartilage degradation within the arthritic joints.

Although arthritis is present in every population and $O A$ is the most common joint disorder, treatment is still limited to a few classes of drugs, primarily nonsteroidal anti-inflammatory drugs and corticosteroids $[49,50]$. While providing relief from pain, however, none of these agents has been shown to inhibit cartilage breakdown or to inhibit disease progress; they also have varying degrees of gastrointestinal toxicity [51]. Previous studies from our laboratory have shown that green tea inhibited the development of arthritis in a mouse model and also inhibited the production of various inflammatory mediators by human chondrocytes stimulated with IL-1 $\beta$ [30-34]. Studies from other investigators have shown that EGCG inhibits the degradation of human cartilage proteoglycan and type-2 collagen [52] and selectively inhibits the ADAMTS-1, ADAMTS-4, and ADAMTS-5 [53]. In the present study, we determined the effect of EGCG on the induction of the major proinflammatory mediators TNF $\alpha$ and MMP-13 in AGE-BSA-stimulated human 


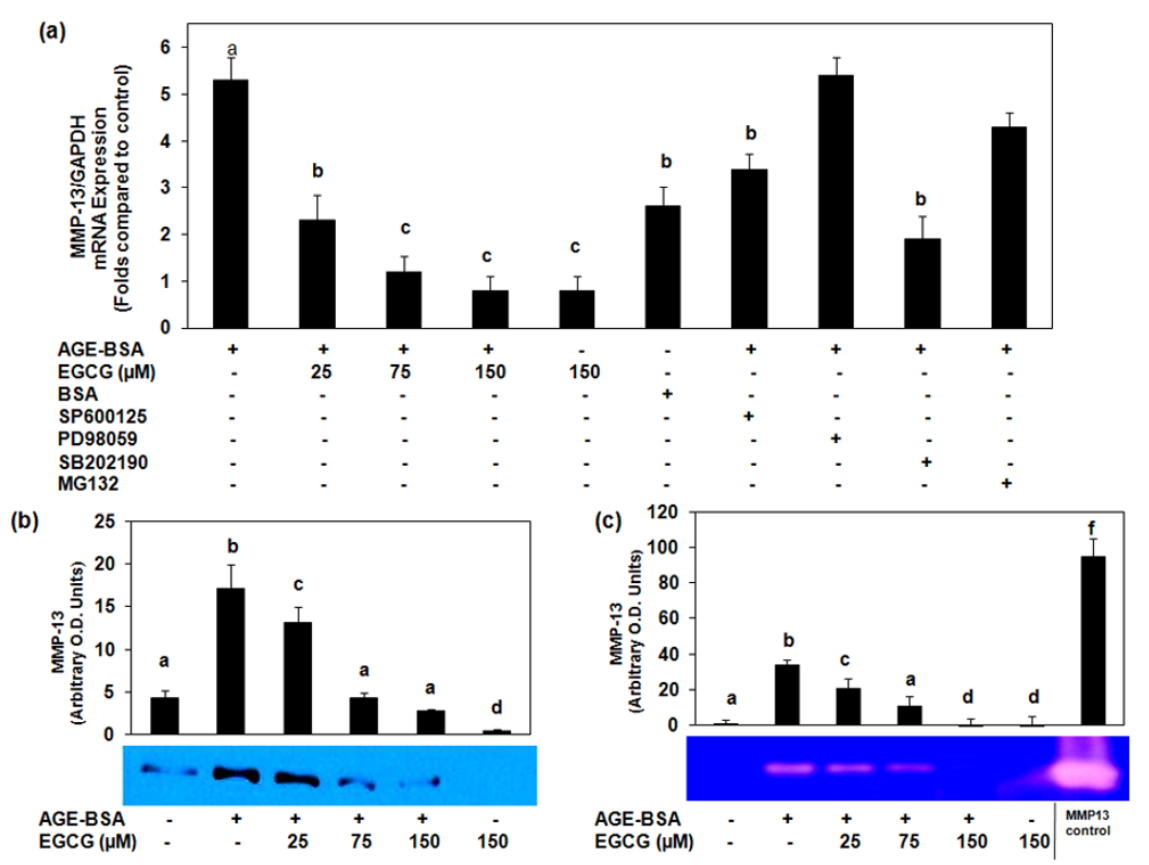

Gene expression and production of matrix metalloproteinase-13 in advanced glycation end product-BSA-stimulated osteoarthritis chondrocytes. (a) Effect of epigallocatechin-3-gallate (EGCG), specific inhibitors for mitogen-activated protein kinases and NF- $\mathrm{KB}$ on the gene expression of matrix metalloproteinase (MMP)-13 in advanced glycation end product (AGE)-BSA-stimulated osteoarthritis (OA) chondrocytes. Primary human chondrocytes were pretreated with EGCG $(25$ to $150 \mu \mathrm{M})$ for 2 hours and were stimulated with AGE-BSA ( $600 \mu \mathrm{g} / \mathrm{ml})$ for 8 hours. Expression of MMP-13 mRNA was normalized to GAPDH and compared with the levels present in control. Concentrations of specific inhibitors of JNK (SP600125), ERK (PD98059), p38 (SB202190) and NF-KB (MG-132) used in these studies were $10 \mu \mathrm{M}, 50 \mu \mathrm{M}, 100 \mu \mathrm{M}$ and $100 \mu \mathrm{M}$, respectively. Native BSA $(600 \mu \mathrm{g} / \mathrm{ml})$ was used as negative control. Results are representative (mean \pm standard error of the mean) of duplicate experiments with chondrocytes obtained from five age-matched and sex-matched OA donors; data without a common letter differ, $P<0.01$. (b), (c) Effect of EGCG on the production of MMP-13 in AGE-BSA-stimulated OA chondrocyte culture medium. Primary chondrocytes were pretreated with EGCG (25 to $150 \mu \mathrm{M})$ for 2 hours and were stimulated with AGE-BSA $(600 \mu \mathrm{g} / \mathrm{ml})$ for 24 hours. MMP-13 production was analyzed in cell culture supernatant by (b) western blotting and (c) gelatin zymography. Equal volumes of culture supernatant were loaded on polyacrylamide gel. The MMP-13 positive control (EMD Chemicals) was also used. Band images were digitally captured and the band intensities (pixels/band) were obtained using the Un-Scan-lt software and are expressed in arbitrary optical density units. Data shown are cumulative of two experiments. OD values presented as mean \pm standard deviation; data without a common letter differ, $P<0.05$.

OA chondrocytes. Almost complete inhibition of both TNF $\alpha$ and MMP-13 expression and production was observed at a concentration of $75 \mu \mathrm{M}$ EGCG $(P<0.01)$ - although these concentrations of EGCG may not be achieved physiologically through oral consumption but may readily be achieved through local administration. Our results presented here demonstrate that EGCG is a potent inhibitor of AGE-BSA-induced expression and production of these inflammatory mediators in human chondrocytes.

The signaling pathways characterized by the MAPKs p38, ERK, and JNK are known to play a potential role in the regulation of inflammatory response $[26,54]$. These are the key players in the molecular and cellular events associated with the pathogenesis of inflammatory arthritis and are being studied as a rational target for arthritis therapy [54]. The activation of RAGE stimulates critical signaling pathways linked to inflammation, resulting in the activation of various inflammatory genes [55]. The interaction of MAPKs and RAGE has been well reported [17]. In the present study we found that EGCG specifically inhibited the AGE-BSA-induced activation of MAPKs and inhibited the expression of TNF $\alpha$ and MMP- 13 by human OA chondrocytes. In addition, the p38-specific, JNKspecific and ERK-specific inhibitors SB202190, SP600125 and PD98059 also reduced TNF $\alpha$ gene and MMP-13 expression in human chondrocytes. These data suggest that EGCG has the potential to inhibit the inflammatory stimuli-induced MAPK activation and the downstream TNF $\alpha$ and MMP-13 gene and protein expression.

Activation of the master transcription factor NF- $\mathrm{kB}$ leads to the coordinated expression of many genes that encode cytokines, chemokines, enzymes, and adhesion molecules involved in mediator synthesis, and the further amplification and perpetuation of the inflammatory reaction $[42,43]$. The NF-kB transcription factors are present in the cytosol in an inactive state, complexed with the inhibitory $\mathrm{I} \mathrm{K} B$ proteins [56]. Activation of $\mathrm{NF}-\mathrm{KB}$ is a common pathway based on the induction of phos- 
(a)

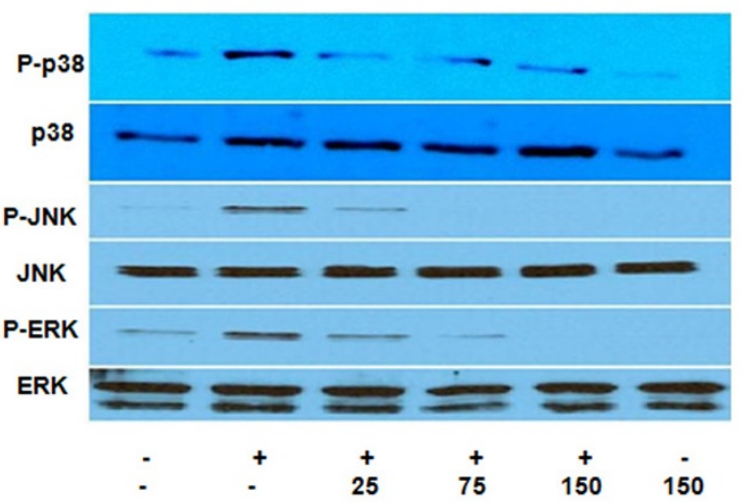

(b)
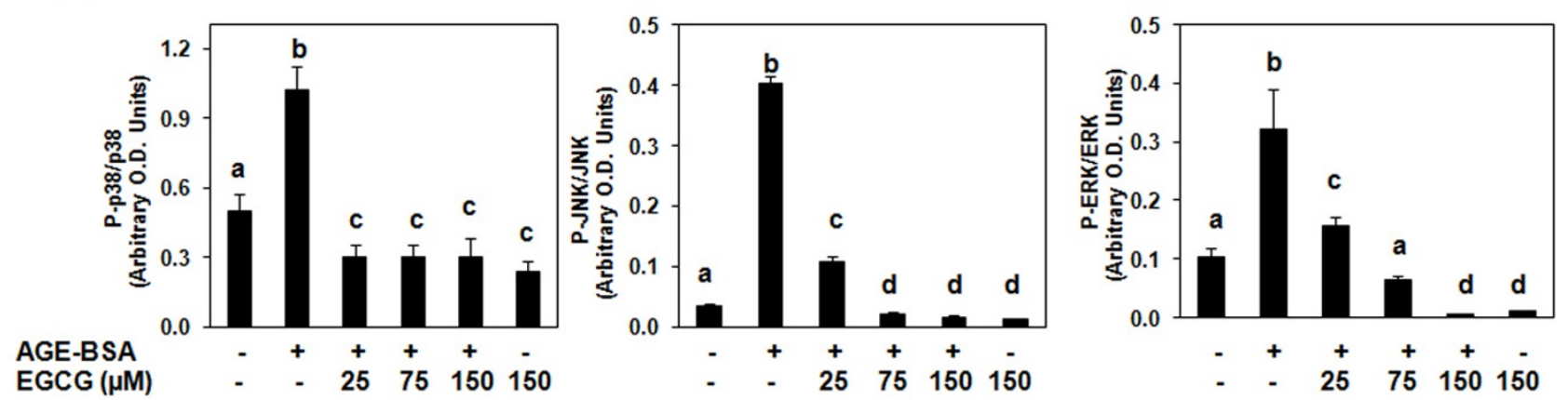

Mitogen-activated protein kinase phosphorylation in advanced glycation end product-BSA-stimulated osteoarthritis chondrocytes. (a) Effect of epigallocatechin-3-gallate (EGCG) on mitogen-activated protein kinase phosphorylation in advanced glycation end product (AGE)-BSA-stimulated osteoarthritis (OA) chondrocytes. After pretreatment with EGCG $(25$ to $150 \mu \mathrm{M})$ for 1 hour at $37^{\circ} \mathrm{C}$, primary human chondrocytes (70 to $80 \%$ confluent) were incubated with AGE-BSA $(400 \mu \mathrm{g} / \mathrm{ml})$ for 45 minutes, and then the phosphorylation of p38, JNK, and ERK was determined by western blot analysis. (b) Band images were digitally captured and the band intensities (pixels/band) were obtained using the Un-Scan-It software and are expressed in arbitrary optical density units. Data shown are cumulative of two experiments. OD values presented as mean \pm standard deviation; data without a common letter differ, $P<0.05$.

phorylation, which mediates proteasomal degradation of $\mathrm{I} B \mathrm{~B}$ [56]. The key regulatory step in this pathway involves activation of a high-molecular-weight IKK complex, whose catalysis is generally carried out by three tightly associated IKK subunits. IKK $\alpha$ and IKK $\beta$ serve as the catalytic subunits of the kinase. IKK $\gamma$ serves as the regulatory subunit [57]. Activation of IKK depends on phosphorylation; serines 177 and 181 in the activation loop of IKK $\beta$ (176 and 180 in IKK $\alpha$ ) are the specific sites whose phosphorylation causes conformational changes resulting in kinase activation [58]. It is also well documented that NF- $\mathrm{KB}$ is known to be involved in AGE-mediated effects of RAGE signaling [17], and that expression of TNF $\alpha$ and MMP-13 gene is dependent on the activation of transcription factor NF-kB $[17,59]$.

Suppression of NF-kB activation has been linked with antiinflammatory activity; we therefore postulated that EGCG mediates its inhibitory effects on TNF $\alpha$ and MMP-13 expressions, at least in part, through the suppression of NF-KB activ- ity. In AGE-BSA-stimulated human OA chondrocytes, EGCG inhibited the degradation of $I \kappa B \alpha$ and nuclear translocation of the NF-kB p65 (Figure 6a,b). In addition, DNA binding activity of nuclear NF-kB p65, as demonstrated by highly sensitive and specific ELISA, was also inhibited in OA chondrocytes. These data further confirm that EGCG attenuates the inflammatory stimuli-induced activation and DNA binding activity of $\mathrm{NF}-\mathrm{KB}$ in human chondrocytes. In order to gain further insight into the mechanism, we used an in vitro kinase activity assay. Our results showed that EGCG inhibited the phosphorylating activity of IKK $\beta$ kinase, indicating that the observed inhibition of NF- $\mathrm{KB}$ in the above studies may have been achieved by inhibition of the IKK activity in OA chondrocytes, causing $I \kappa B \alpha$ to accumulate in the nucleus.

In the present article we report for the first time that EGCG, the most abundant and biologically active catechin of green tea, inhibits the inflammatory activity of AGE-BSA-stimulated human OA chondrocytes. This is achieved by blocking MAPKs 
(a)
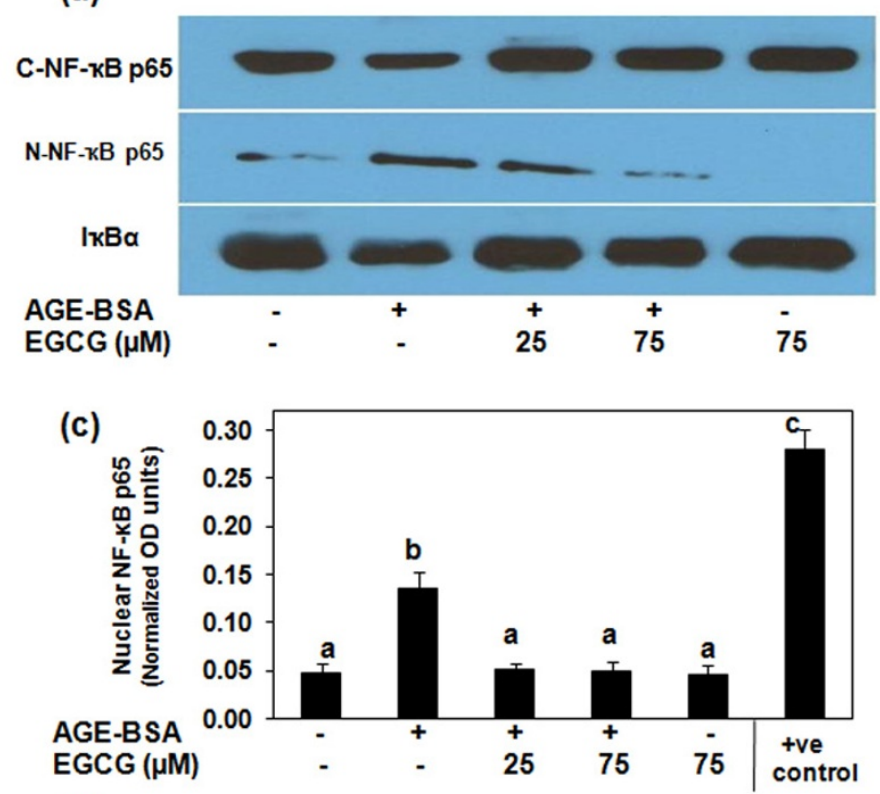

(d)

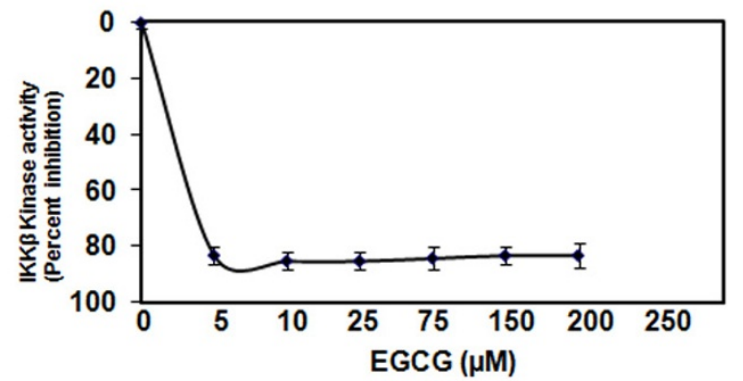

(b)
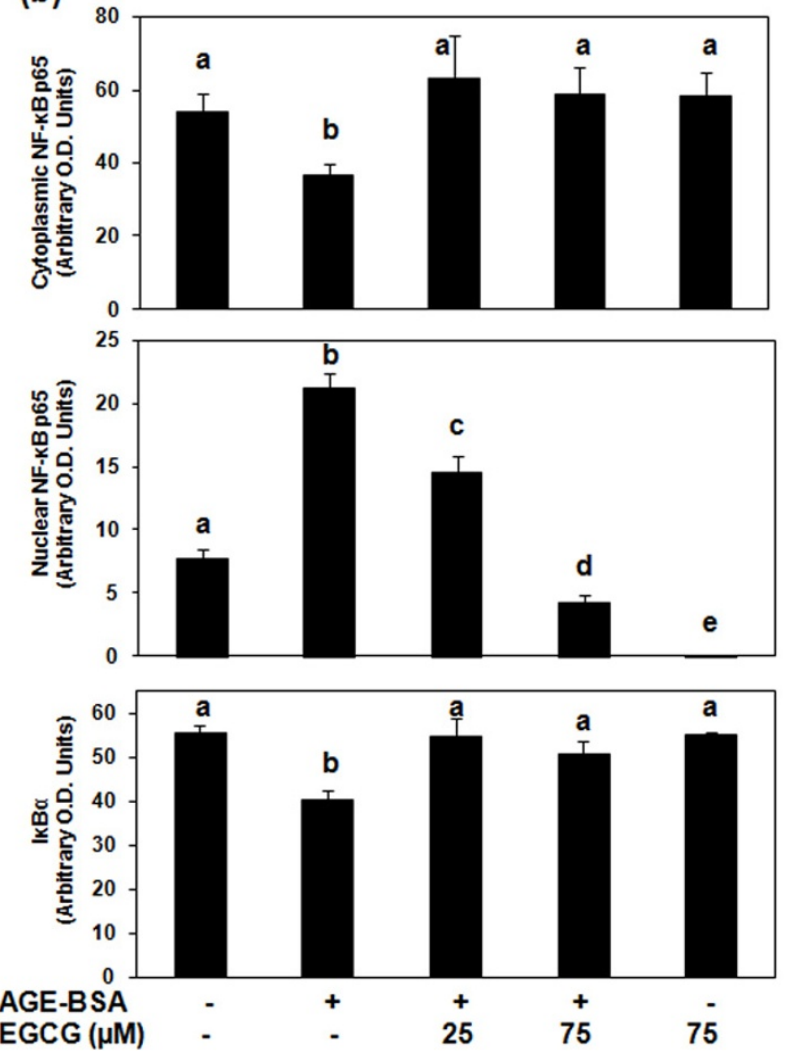

Epigallocatechin-3-gallate inhibits activation and DNA binding of NF- $\mathrm{KB}$ in advanced glycation end product-BSA-stimulated osteoarthritis chondrocytes. Primary chondrocytes ( 70 to $80 \%$ confluent) were pretreated with epigallocatechin-3-gallate (EGCG) ( 25 and $75 \mu \mathrm{M})$ for 2 hours and were stimulated by advanced glycation end product (AGE)-BSA $(600 \mu \mathrm{g} / \mathrm{ml})$. (a) $\mathrm{l} \mathrm{\kappa B} \alpha$ degradation and NF- $\mathrm{KB}$ translocation were analyzed by western

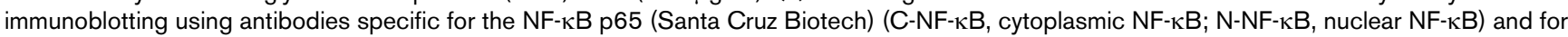
$I_{\kappa} B \alpha$ (Santa Cruz Biotech). (b) Band intensities were obtained as described above. Data shown are cumulative of three experiments, and the optical density values (pixels/band) presented as mean \pm standard deviation. (c) Activated NF- $\kappa B$ p65 in the nucleus was determined by the highly specific Transcription Factor ELISA kit (Panomics). The positive control nuclear extract supplied with the kit was used. Data are representative of two experiments and presented as mean \pm standard deviation; data without a common letter differ, $P<0.05$. (d) EGCG inhibited the IKK $\beta$ kinase activity in vitro. IKK $\beta$ kinase activity was determined in the absence or presence of EGCG (5 to $200 \mu \mathrm{M}$ ) using the HTScan ${ }^{\circledR}$ IKK $\beta$ Kinase Assay Kit (Cell Signaling Technology). Each point is representative of three individual kinase assays and presented as mean \pm standard deviation.

and NF- $\kappa \mathrm{B}$ activation in human chondrocytes. Our results also point out that inhibition of NF- $\kappa B$ was achieved by inhibiting the degradation of the inhibitor $I \kappa B \alpha$ in the cytoplasm of human $\mathrm{OA}$ chondrocytes as previously reported [31]. As TNF $\alpha$ and MMP-13 genes are NF- $\mathrm{KB}$ dependent, inhibition of NF- $\kappa B$ also inhibits their expression and production in AGEBSA-stimulated chondrocytes.

There are a number of studies documenting the beneficial health effects of green tea consumption. Most of these studies place emphasis on the anticancer properties of green tea [2729], which have now been attributed, at least in part, to the ability of green tea polyphenols to inhibit the inflammatory processes [30]. To this, based on our results, we can add that EGCG is a potent inhibitor of AGE-BSA-induced induction of TNF $\alpha$ and MMP-13 at a physiologically achievable concentration ( $25 \mu \mathrm{M}$; see Figures $3 \mathrm{a}$ and $4 \mathrm{a}$ ) - but for more complete inhibition higher dose is needed. We therefore conclude that inhibition of arthritis following green tea consumption in an animal model [30] and inhibition of cartilage degradation and production of inflammatory mediators by EGCG may be the result of inhibition of some of the matrix-degrading enzymes/factors at the mRNA level through inhibition of NF- $\mathrm{KB}$. It is therefore tempting to suggest that green tea polyphenol EGCG or compounds derived from it may serve as lead agents in the design of more potent and effective inhibitors of proinflammatory 
cytokines and collagenases for use therapeutically to block cartilage degradation in $\mathrm{OA}$.

\section{Conclusions}

The present article is the first report that shows green tea catechin EGCG inhibits the inflammatory activity against AGEinduced activation of human $O A$ chondrocytes. The results of the present study indicate that EGCG inhibits AGE-BSAinduced upregulation of TNF $\alpha$ and MMP-13 viainhibiting the MAPK and NF- $\mathrm{B}$ activation in human OA chondrocytes. EGCG or EGCG-derived compounds may be of value for the treatment of inflammatory arthritis in which AGEs play an active role.

\section{Competing interests}

The authors declare that they have no competing interests.

\section{Authors' contributions}

ZR carried out the experimental work, data collection and interpretation, and manuscript preparation. ANA, NA, SR, and FRV carried out the experimental work and collection of data. TMH conceived of the study design, coordinated the studies, data interpretation and manuscript preparation. All authors have read and approved the final manuscript.

\section{Acknowledgements}

The present work was supported in part by NIH/NCCAM grant AT003267 and by funds from the University of South Carolina, Columbia.

\section{References}

1. Felson DT, Lawrence RC, Dieppe PA, Hirsch R, Helmick CG, Jordan JM, Kington RS, Lane NE, Nevitt MC, Zhang $Y$, Sowers $M$, McAlindon T, Spector TD, Poole AR, Yanovski SZ, Ateshian G, Sharma L, Buckwalter JA, Brandt KD, Fries JF: Osteoarthritis: new insights. I. The disease and its risk factors. Ann Intern Med 2000, 133:635-646

2. Felson DT, Zhang Y: An update on the epidemiology of knee and hip osteoarthritis with a view to prevention [review]. Arthritis Rheum 1998, 41:1343-1355.

3. Verziil N, Bank RA, TeKoppele JM, DeGroot J: Ageing and osteoarthritis: a different perspective. Curr Opin Rheumatol 2003, 15:616-622.

4. Verzijl N, DeGroot J, Thorpe SR, Bank RA, Shaw JN, Lyons TJ, Bijlsma JW, Lafeber FP, Baynes JW, TeKoppele JM: Effect of collagen turnover on the accumulation of advanced glycation end products. J Biol Chem 2000, 275:39027-39031.

5. Bank RA, Bayliss MT, Lafeber FP, Maroudas A, TeKoppele JM: Ageing and zonal variation in post-translational modification of collagen in normal human articular cartilage: the agerelated increase in non-enzymatic glycation affects biomechanical properties of cartilage. Biochem J 1998, 330:345-351

6. Verzijl N, DeGroot J, Oldehinkel E, Bank RA, Thorpe SR, Baynes JW, Bayliss MT, Biilsma JW, Lafeber FP, Tekoppele JM: Agerelated accumulation of Maillard reaction products in human articular cartilage collagen. Biochem J 2000, 350:381-387.

7. Verzijl N, DeGroot J, Ben ZC, Brau-Benjamin O, Maroudas A, Bank RA, Mizrahi J, Schalkwijk CG, Thorpe SR, Baynes JW, Bijlsma JW, Lafeber FP, TeKoppele JM: Crosslinking by advanced glycation end products increases the stiffness of the collagen network in human articular cartilage: a possible mechanism through which age is a risk factor for osteoarthritis. Arthritis Rheum 2002, 46:114-123.

8. DeGroot J, Bank RA, Tchetverikov I, Verzijl N, TeKoppele JM: Molecular markers for osteoarthritis: the road ahead. Curr Opin Rheumato/ 2002, 14:585-589.
9. DeGroot J, Verzijl N, Bank RA, Lafeber FP, Bijlsma JW, TeKoppele $\mathrm{JM}$ : Age-related decrease in proteoglycan synthesis of human articular chondrocytes: the role of nonenzymatic glycation. Arthritis Rheum 1999, 42:1003-1009.

10. DeGroot J, Verzijl N, Wenting-van Wijk MJ, Jacobs KM, van El B, van Roermund PM, Bank RA, Bijlsma JW, TeKoppele JM, Lafeber FP: Accumulation of advanced glycation end products as a molecular mechanism for aging as a risk factor in osteoarthritis. Arthritis Rheum 2004, 50:1207-1215.

11. Steenvoorden MM, Huizinga TW, Verzijl N, Bank RA, Ronday HK, Luning HA, Lafeber FP, Toes RE, DeGroot J: Activation of receptor for advanced glycation end products in osteoarthritis leads to increased stimulation of chondrocytes and synoviocytes. Arthritis Rheum 2006, 54:253-263.

12. McCance DR, Dyer DG, Dunn JA, Bailie KE, Thorpe SR, Baynes JW, Lyons TJ: Maillard reaction products and their relation to complications in insulin-dependent diabetes mellitus. J Clin Invest 1993, 91:2470-2478.

13. Waine H, Nevinny D, Rosenthal J, Joffe IB: Association of osteoarthritis and diabetes mellitus. Tufts Folia Med 1961, 7:13-19.

14. Campbell WL, Feldman F: Bone and soft tissue abnormalities of the upper extremity in diabetes mellitus. $A m$ J Roentgenol Radium Ther Nucl Med 1975, 124:7-16.

15. Bagge E, Bjelle A, Eden S, Svanborg A: Factors associated with radiographic osteoarthritis: results from the population study 70-year-old people in Göteborg. J Rheumatol 1991, 18:1218-1222.

16. Sunahori K, Yamamura M, Yamana J, Takasugi K, Kawashima M, Makino $\mathrm{H}$ : Increased expression of receptor for advanced glycation end products by synovial tissue macrophages in rheumatoid arthritis. Arthritis Rheum 2006, 54:97-104.

17. Loeser RF, Yammani RR, Carlson CS, Chen H, Cole A, Im HJ, Bursch LS, Yan SD: Articular chondrocytes express the receptor for advanced glycation end products: potential role in osteoarthritis. Arthritis Rheum 2005, 52:2376-2385.

18. Nah SS, Choi IY, Yoo B, Kim YG, Moon H, Lee C: Advanced glycation end products increases matrix metalloproteinase $-1,-3$, and -13 , and TNF- $\alpha$ in human osteoarthritic chondrocytes. FEBS Lett 2007, 581:1928-1932.

19. Steenvoorden MM, Huizinga TW, Verzijl N, Bank RA, Ronday HK, Luning HA, Lafeber FP, Toes RE, DeGroot J: Activation of receptor for advanced glycation end products in osteoarthritis leads to increased stimulation of chondrocytes and synoviocytes. Arthritis Rheum 2006, 54:253-263.

20. Nah SS, Choi IY, Lee CK, Oh JS, Kim YG, Moon HB, Yoo B: Effects of advanced glycation end products on the expression of COX-2, $\mathrm{PGE}_{2}$ and NO in human osteoarthritic chondrocytes. Rheumatology (Oxford) 2008, 47:425-431.

21. Valencia JV, Weldon SC, Quinn D, Kiers GH, DeGroot J, TeKoppele JM, Hughes TE: Advanced glycation end product ligands for the receptor for advanced glycation end products: biochemical characterization and formation kinetics. Anal Biochem 2004, 324:68-78.

22. Schmitt A Schmitt J, Münch G, Gasic-Milencovic J: Characterization of advanced glycation end products for biochemical studies: side chain modifications and fluorescence characteristics. Anal Biochem 2005, 338:201-215.

23. Schmitt A, Nöller J, Schmitt J: The binding of advanced glycation end products to cell surfaces can be measured using beadreconstituted cellular membrane proteins. Biochim Biophys Acta 2007, 1768:1389-1399.

24. Farboud B, Aotaki-Keen A, Miyata T, Hjelmeland LM, Handa JT: Development of a polyclonal antibody with broad epitope specificity for advanced glycation end products and localization of these epitopes in Bruch's membrane of the aging eye. Mol Vis 1999, 5:11.

25. Sternlicht MD, Werb Z: How matrix metalloproteinases regulate cell behavior [review]. Annu Rev Cell Dev Biol 2001, 17:463-516

26. Rasheed Z, Haqqi TM: Update on targets of biologic therapies for rheumatoid arthritis. Curr Rheum Rev 2008, 4:246-253.

27. Khan N, Mukhtar H: Tea polyphenols for health promotion. Life Sci 2007, 81:519-533.

28. Siddiqui IA, Malik A, Adhami VM, Asim M, Hafeez BB, Sarfaraz S, Mukhtar $H$ : Green tea polyphenol EGCG sensitizes human prostate carcinoma LNCaP cells to TRAIL-mediated apoptosis 
and synergistically inhibits biomarkers associated with angiogenesis and metastasis. Oncogene 2008, 27:2055-2063.

29. Siddiqui IA, Shukla Y, Adhami VM, Sarfaraz S, Asim M, Hafeez BB, Mukhtar $\mathrm{H}$ : Suppression of NF $\kappa B$ and its regulated gene products by oral administration of green tea polyphenols in an autochthonous mouse prostate cancer model. Pharm Res 2008, 25:2135-2142.

30. Haqqi TM, Anthony DD, Gupta S, Ahmed N, Lee MS, Kumar GK, Mukhtar $\mathrm{H}$ : Prevention of collagen-induced arthritis in mice by a polyphenolic fraction from green tea. Proc Natl Acad Sci USA 1999, 96:4524-4529.

31. Singh R, Ahmed S, Islam N, Goldberg VM, Haqqi TM: Epigallocatechin-3-gallate inhibits interleukin-1 $\beta$-induced expression of nitric oxide synthase and production of nitric oxide in human chondrocytes: suppression of nuclear factor kappa B activation by degradation of the inhibitor of nuclear factor kappa B. Arthritis Rheum 2002, 46:2079-2086.

32. Ahmed S, Wang N, Lalonde M, Goldberg VM, Haqqi TM: Green tea polyphenol epigallocatechin-3-gallate (EGCG) differentially inhibits interleukin-1 $\beta$-induced expression of matrix metalloproteinase-1 and -13 in human chondrocytes. J Pharmacol Exp Ther 2004, 308:767-773.

33. Singh R, Ahmad S, Malemud CJ, Goldberg VM, Haqqi TM: Epigallocatechin-3-gallate selectively inhibits interleukin-1-induced activation of mitogen activated protein kinase subgroup c-Jun $\mathrm{N}$-terminal kinase in human osteoarthritis chondrocytes. J Orthop Res 2003, 21:102-109.

34. Ahmed S, Rahman A, Hasnain A, Lalonde M, Goldberg VM, Haqqi TM: Green tea polyphenol epigallocatechin-3-gallate inhibits the IL-1 $\beta$-induced activity and expression of cyclooxygenase2 and nitric oxide synthase-2 in human chondrocytes. Free Radic Biol Med 2002, 33:1097-1105.

35. Mandel S, Weinreb O, Amit T, Youdim MB: Cell signaling pathways in the neuroprotective actions of the green tea polyphenol (-)-epigallocatechin-3-gallate: implications for neurodegenerative diseases. J Neurochem 2004, 88:1555-1569.

36. Armstrong CG, Mow VC: Variations in the intrinsic mechanical properties of human articular cartilage with age, degeneration, and water content. J Bone Joint Surg Am 1982, 64:88-94.

37. Shukla M, Gupta K, Rasheed Z, Khan KA, Haqqi TM: Bioavailable constituents/metabolites of pomegranate (Punica granatum L) preferentially inhibit COX2 activity ex vivo and IL-1 $\beta$-induced $\mathrm{PGE}_{2}$ production in human chondrocytes in vitro. J Inflamm (Lond) 2008, 5:9.

38. Mankin HJ, Dorfman H, Lippiello L, Zarins A: Biochemical and metabolic abnormalities in articular cartilage from osteoarthritic human hips. II. Correlation of morphology with biochemical and metabolic data. J Bone Joint Surg Am 1971, 53:523-537.

39. Laemmli UK: Cleavage of structural proteins during the assembly of the head of bacteriophage T4. Nature 1970, 227:680-685.

40. Pfaffl MW: A new mathematical model for relative quantification in real-time RT-PCR. Nucleic Acid Res 2001, 29:e45.

41. Gupta K, Shukla M, Cowland JB, Malemud CJ, Haqqi TM: Neutrophil gelatinase-associated lipocalin is expressed in osteoarthritis and forms a complex with matrix metalloproteinase 9. Arthritis Rheum 2007, 56:3326-3335.

42. Rasheed Z, Akhtar N, Anbazhagan AN, Ramamurthy S, Shukla M, Haqqi TM: Polyphenol-rich pomegranate fruit extract (POMx) suppresses $\mathrm{PMACl}$-induced expression of pro-inflammatory cytokines by inhibiting the activation of MAP Kinases and NF$\kappa B$ in human KU812 cells. J Inflamm (Lond) 2009, 6:1.

43. Hafeez BB, Ahmed S, Wang N, Gupta S, Zhang A, Haqqi TM: Green tea polyphenols-induced apoptosis in human osteosarcoma SAOS-2 cells involves a caspase-dependent mechanism with downregulation of nuclear factor-kappaB. Toxicol Appl Pharmacol 2006, 216:11-19.

44. de Crombrugghe B, Lefebvre V, Behringer RR, Bi W, Murakami S, Huang W: Transcriptional mechanisms of chondrocyte differentiation. Matrix Bio/ 2000, 19:389-394.

45. Poole AR: Cartilage in health and disease. In Arthritis and Allied Conditions: A Textbook of Rheumatology 14th edition. Edited by: Koopman W. Philadelphia: Lippincott Williams \& Wilkins; 2001:226-284
46. Pelletier JP, Martel-Pelletier J, Abramson SB: Osteoarthritis, an inflammatory disease: potential implication for the selection of new therapeutic targets [review]. Arthritis Rheum 2001, 44:1237-1247.

47. Weightman BO, Freeman MA, Swanson SA: Fatigue of articular cartilage. Nature 1973, 244:303-304.

48. Kempson GE: The mechanical properties of articular cartilage. In The Joints and Synovial Fluid Edited by: Sokoloff L. New York: Academic Press; 1980:177-238.

49. Fendrick AM, Greenberg BP: A review of the benefits and risks of nonsteroidal anti-inflammatory drugs in the management of mild-to-moderate osteoarthritis. Osteopath Med Prim Care 2009, 3:1.

50. Bellamy N, Campbell J, Robinson V, Gee T, Bourne R, Wells G: Intraarticular corticosteroid for treatment of osteoarthritis of the knee. Cochrane Database Syst Rev 2006, 2:CD005328.

51. Fries JF, Bruce B: Rates of serious gastrointestinal events from low dose use of acetylsalicylic acid, acetaminophen, and ibuprofen in patients with osteoarthritis and rheumatoid arthritis. $J$ Rheumatol 2003, 30:2226-2233.

52. Adcocks $C$, Collin $P$, Buttle DJ: Catechins from green tea (Camellia sinensis) inhibit bovine and human cartilage proteoglycan and type-II collagen degradation in vitro. J Nutr 2002 , 132:341-346.

53. Vankemmelbeke MN, Jones GC, Fowles C, llic MZ, Handley CJ, Day AJ, Knight CG, Mort JS, Buttle DJ: Selective inhibition of ADAMTS $-1,-4$ and -5 by catechin gallate esters. Eur J Biochem 2003, 270:2394-2403.

54. Thalhamer T, McGrath MA, Harnett MM: MAPKs and their relevance to arthritis and inflammation. Rheumatology 2008 47:409-414

55. Hofmann MA, Drury S, Fu C, Qu W, Taguchi A, Lu Y, Avila C, Kambham N, Bierhaus A, Nawroth P, Neurath MF, Slattery T, Beach D, McClary J, Nagashima M, Morser J, Stern D, Schmidt AM: RAGE mediates a novel proinflammatory axis: a central cell surface receptor for S100/calgranulin polypeptides. Cell 1999, 97:889-901.

56. Finco TS, Beg AA, Baldwin AS Jr: Inducible phosphorylation of I $\mathrm{B} \alpha$ is not sufficient for its dissociation from NF- $\kappa B$ and is inhibited by protease inhibitors. Proc Natl Acad Sci USA 1994, 91:11884-11888.

57. Zandi E, Rothwarf DM, Delhase M, Hayakawa M, Karin M: The IאB kinase complex (IKK) contains two kinase subunits, IKK $\alpha$ and IKK $\beta$, necessary for I $\mathrm{B}$ phosphorylation and NF- $\mathrm{KB}$ activation. Cell 1997, 91:243-252.

58. DiDonato JA, Hayakawa M, Rothwarf DM, Zandi E, Karin M: A cytokine-responsive $I_{\kappa} B$ kinase that activates the transcription factor NF-кB. Nature 1997, 388:548-554.

59. Azzolina $A$, Bongiovanni $A$, Lampiasi $N$ : Substance $P$ induces TNF- $\alpha$ and IL- 6 production through NF $\kappa B$ in peritoneal mast cells. Biochim Biophys Acta 2003, 1643:75-83. 